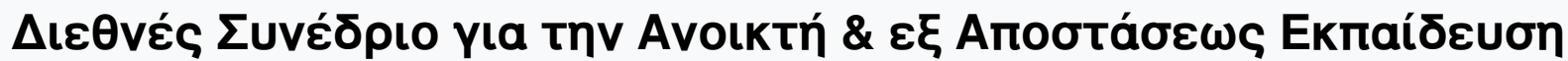

Tón. 7, Ap. 1A (2013)

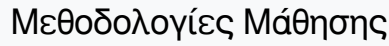

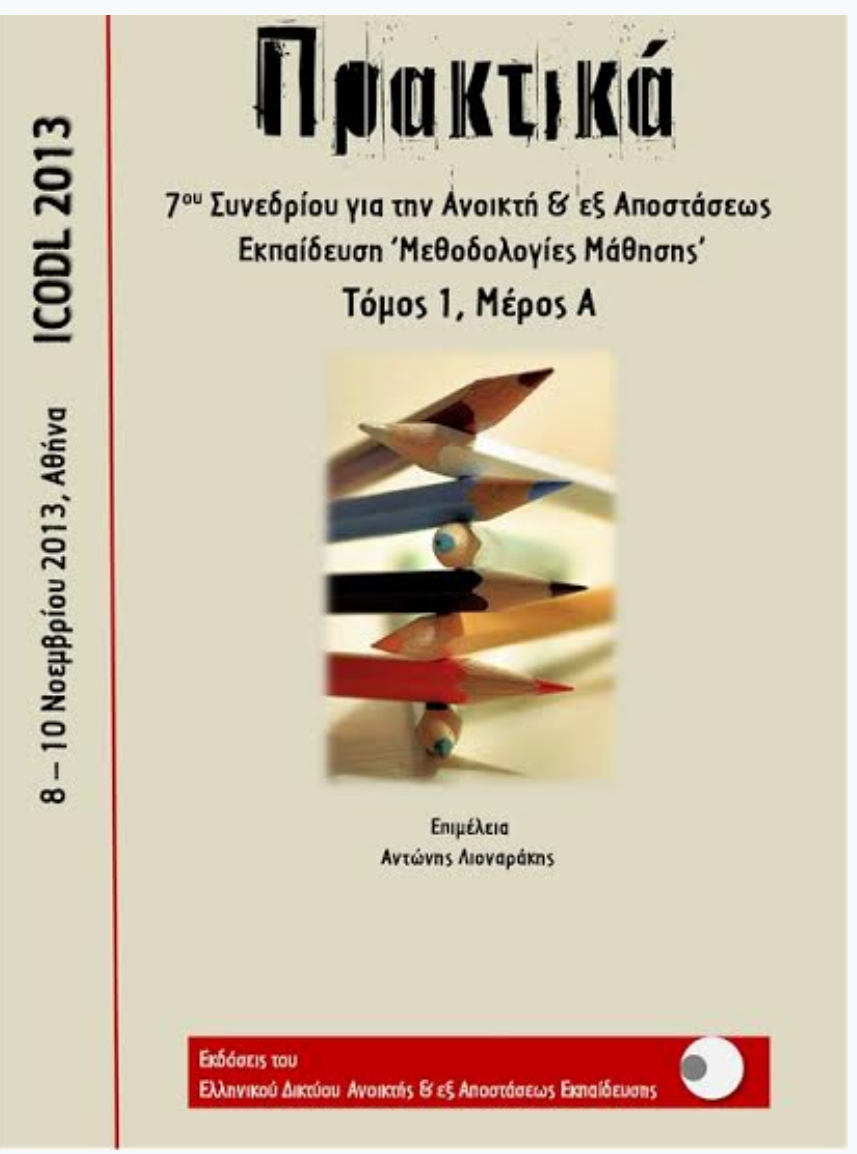

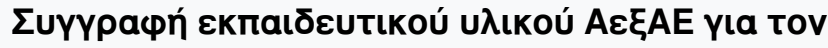

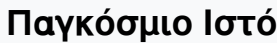

Antonios Andreatos

doi: $10.12681 /$ icodl. 546 


\title{
Authoring ODL educational material for the Web
}

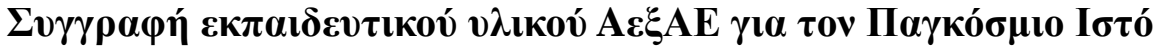

\author{
Antonios Andreatos \\ Division of Computer Engineering \& Information Science \\ Hellenic Air Force Academy, GREECE \\ aandreatos@gmail.com, informatics.hafa@haf.gr
}

\begin{abstract}
This paper discusses some critical issues for writing educational material for Open and Distance Learning (ODL) to be posted on the Web. ODL material is interactionoriented; so is the Web. In addition, the Web offers some unique characterics which, when taken into account, will offer significal advantages to the educational material of ODL. This is important for authoring material in digital format for the Web, right from the beginning, as well as, for transferring to the Web existing material written in traditional format (i.e., print). There is a number of pedagogical as well as technological disciplines which must be taken into account. These are: the principles of ODL educational material authoring; the principles of composition and presentation of an ODL porftolio; measurements concerning online reader's behaviour; web usability rules; metadata tagging schemes for automatic processing by computers, and learning styles. This paper is initially based on a theoretical discussion and brings forth some important, practical guidelines for authoring ODL educational material for the Web, in order to improve the learning outcome.
\end{abstract}

Keywords: $O D L$ educational material, Web, Learning Management Systems, learning styles, new media, ICT, CMS.

\section{Пєрі́ $\eta \psi \eta$}

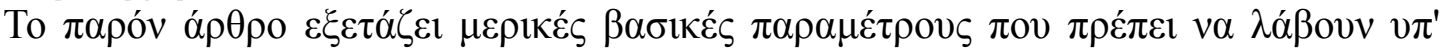

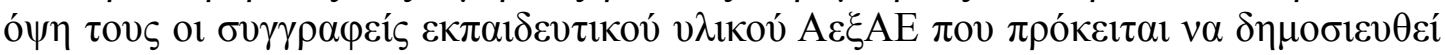

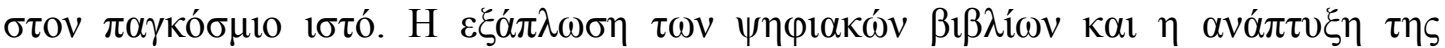

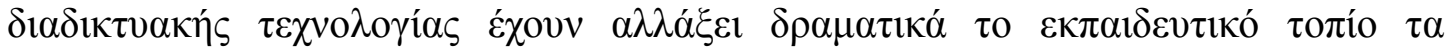

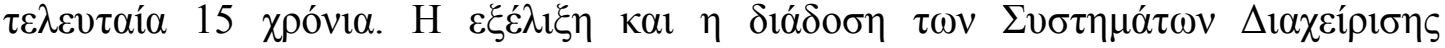

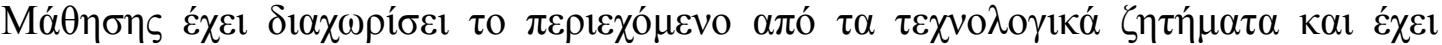

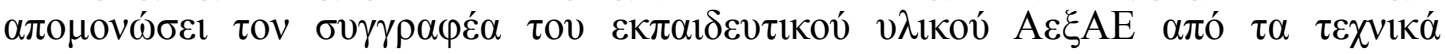
$\zeta \eta \tau \eta ́ \mu \alpha \tau$.

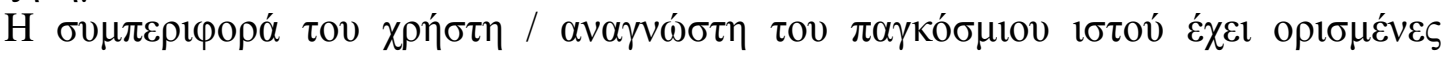

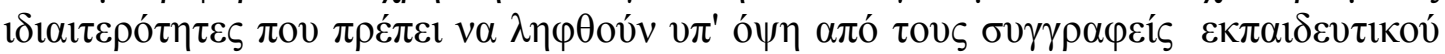

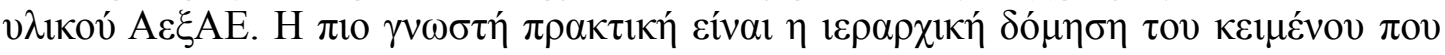

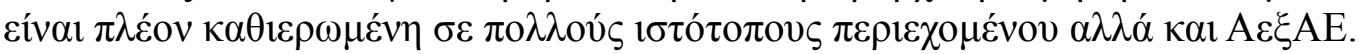

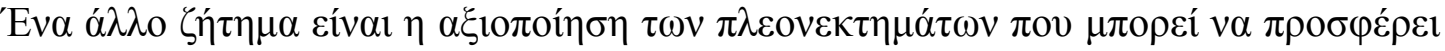

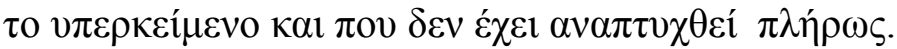

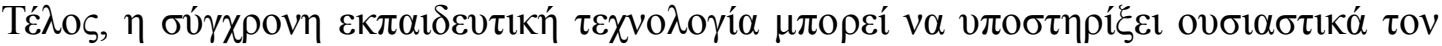

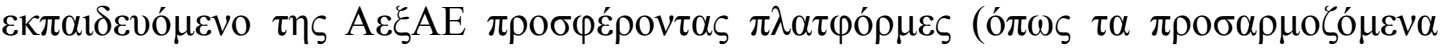

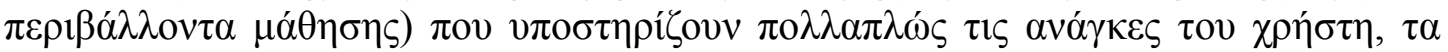




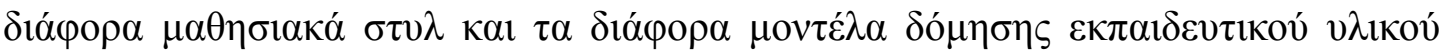
A $\varepsilon \xi A E$.

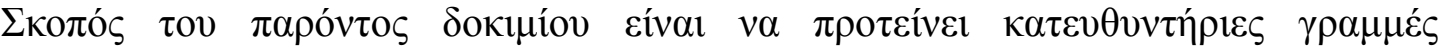

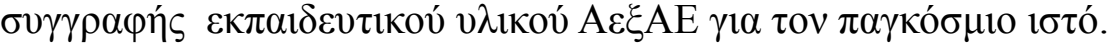

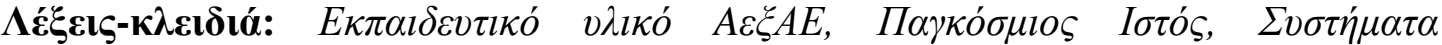

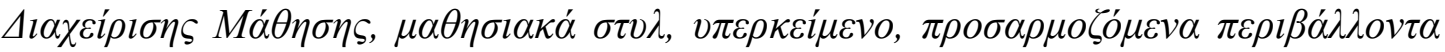
$\mu \dot{\alpha} \theta \eta \sigma \eta \varsigma$.

\section{Introduction}

When it comes to share Open and Distance Learning (ODL) educational material through the Web, merely posting the PDF version of a printed textbook or copying the text and images to a web page, is problematic. There is a substantial difference between posting PDFs written conventionally and offering correctly structured ODL material online. This is because the online user's behaviour is subject to special rules and it is completely different compared to a reader's behaviour reading a printed book. In this article we shall attempt to compose a set of basic guidelines, taking into account principles from various fields, namely:

- authoring ODL educational material;

- presentation of an ODL porftolio;

- online reader's behaviour;

- web usability and

- learning styles.

Based on the above, we discuss the structure of ODL educational material to be offered via the Web, for achieving the maximum learning outcome.

The rest of this paper is structured as follows: section 2 presents some details concerning the online user's behaviour; section 3 presents the special characterics of ODL educational material; section 4 presents some interesting possibilities of hypertext from the ODL viewpoint; section 5 introduces learning styles and presents implications for supporting ODL learners of different learning styles using proper ICT technologies. Section 6 contains the conclusion and a discussion.

\section{Online user's behaviour}

An online reader's behaviour is different than the traditional text reader's behaviour (Nielsen, 2000). Most online users are not as patient as they are when they study printed matter; they act as if they are in a hurry. This fact imposes some guidelines for the authors of ODL educational material.

It has been measured that (Nielsen, 2000):

- $79 \%$ of the users scan the page because they find it painful to read too much text on line; only $16 \%$ read word-by-word.

- Reading from screen is $25 \%$ slower and much more boring than reading from paper. Internet users are impatient and critical; they want to find what they are looking for, as soon as possible. Also, they are not willing to read long pages online. The Web is an informal and immediate medium compared to print; users appreciate an informal, "light" writing style, simple sentences and short paragraphs. Therefore, it has been suggested that Web content should have half of the word count of the corresponding paper version (Nielsen, 2000). Note that these characteristics (short paragraphs, informal and friendly language, etc.) are also met in ODL textbooks (Race, 1989).

As a result, professional sites follow a "pyramid-like" hierachical model, where first 
comes the title and subtitle, then the abstract and finally the full text (the details). The reader will choose to read the full text only after having found interesting the previous parts (Nielsen, 2000). ODL authors should not underestimate these issues.

This hierachical model, followed strictly by many types of sites, has also been adopted by many academic journals, such as "Open Education", the Greek e-journal for Open and Distance Education and Educational Technology published by the Hellenic Network of Open and Distance Education (http://journal.openet.gr/index.php/openjournal). The International Review of Research in Open and Distance Learning, a refereed e-journal of the Athabasca University in Canada, (http://www.irrodl.org/index.php/irrodl/index) constitutes another example.

The structure of the content of these e-journals is hierarchical, consisting of three levels: the first level is the table of contents of each issue; the second level is the abstract of the selected article; finally the third level is the full text in pdf. The reader may choose to read the abstract in order to decide whether he/she is interested in reading the full text. Similarly, in ODL online material, the reader should be able to see an overview (useful in understanding what it is about at a glance or to recall the material at the end of the study like reading the synopsis) or the full text (e.g., when studying). More levels could also be used. This is difficult with printed books; however, the existence of this feature at the Table of contens (detailed contens plus contens at a glance) implies exactly this need.

In summary, online reader's behaviour is different than the traditional text reader's behaviour; online readers are not willing to read long pages online. Professional sites follow a hierachical model which gives online users an overview of the whole content. Readers can get advantage of this feature in their study.

\section{The special characterics of ODL educational material}

The ODL student is based on the educational portfolio for many tasks which, in faceto-face education, would be accomplished by the educator. For example, tasks like guiding the student, definition of objectives and expected results, assessment, feedback, answering FAQs, additional bibliography and sources for parallel or further study, should be included in the ODL educational portfolio.

ODL material must take into account the facts that concentration span is limited and that adult learners usually do not avail large continuous periods for study; therefore, text should be broken into small, manageable sections (Race, 1898). Moreover, text monotonicity should be broken using pictures, images, charts etc., i.e., other forms of educational material described in the West-Lionarakis model (Lionarakis, 2001). These requirements match corresponding Web usability rules like "write short paragraphs", "use colours", "incorporate multimedia moderately", "support search and navigation", "avoid too much scrolling", etc. (Nielsen, 2000).

ODL textbooks must be easily readable, analytic and user-friendly; they must not leave questions or ambiguities; they must lead to the consolidation of study; and they must be properly organised (Race, 1989). Moreover, ODL textbooks must contain a set of additional texts supporting the above goals. However, it is difficult for a textbook to support different learning styles (Honey \& Mumford, 1992) at the same time.

Another issue is that of additional portfolio (readings or "parallel texts" in Greek). In higher education the single textbook practice has been abandoned; instructors today use additional bibliography (tutorials, papers, books, etc.) and multimedia resources in various formats (Lionarakis, Panagiotakopoulos \& Xenos, 2005). 
The additional portfolio should be polymoprhic (i.e., offered in a variety of formats) so that it makes study interesting, as well as, highly portable, so that learners could exploit their time while travelling, using everyday portable equipment such as tablets, mobile phones, etc. Hence, educational material format is crucial and should maximise learning freedom and effectiveness.

When the course portfolio consists of many different objects, a Study Guide is needed to help learners find their way through the material. The study guide should contain comments about all items, including bibliography items and it should be posted prominently. Moreover, all objects should contain proper metadata in order to facilitate searchability, reusability and automatic processing by computers (Andreatos \& Katsoulis, 2012).

In summary, ODL authors should be aware of the ODL text requirements; except of the main text, additional multimedia material is needed to compose an ODL course portfolio (Lionarakis, 2001); the additional portfolio should be polymoprhic, as well as, highly portable in order to support learners on the go and different learning styles.

\section{The power of the Web and hypertext}

Hypertext offers a bunch of advantages over printed text which can facilitate the study and enhance the learning experience.

Hyperlinks enable an easy-to-use and flexible connection to other pages on the Web; readers can follow hyperlinks to access additional information on specific terms which, usually underlined or differently coloured, in order to be easily recognised. In traditional ODL paper texts, this was achieved with the use of frames embedded in the main text. According to the West-Lionarakis model (Lionarakis, 2001), these are the Over-texts $(\varepsilon \pi \imath \kappa \varepsilon i ́ \mu \varepsilon v \alpha)$ and the Retro-texts $(\pi \varepsilon \rho ı \kappa \varepsilon i ́ \mu \varepsilon v \alpha)$. The difference is that in paper, the set of frames or Over-texts and Retro-texts that can be used is limited due to space and cost limitations, while in an online text there is no limit. Moreover, computer programmes which automatically recognise terms and add hyperlinks from selected sources (e.g. online ecyclopaedias and dictionaries) exist, to make the author's job (and life) much easier (for instance see (Andreatos \& Katsoulis, 2011)). Figure 1 presents an example of an online dictionary (http://www.webopedia.com) which presents to the reader hypertext with links to other lemmas within it. Notice that on the right hand side, a list of related hyperlinks appears. Presenting the Table of Contents in the same way would give an overview of the material to the readers and would enable them to easily navigate through it. 


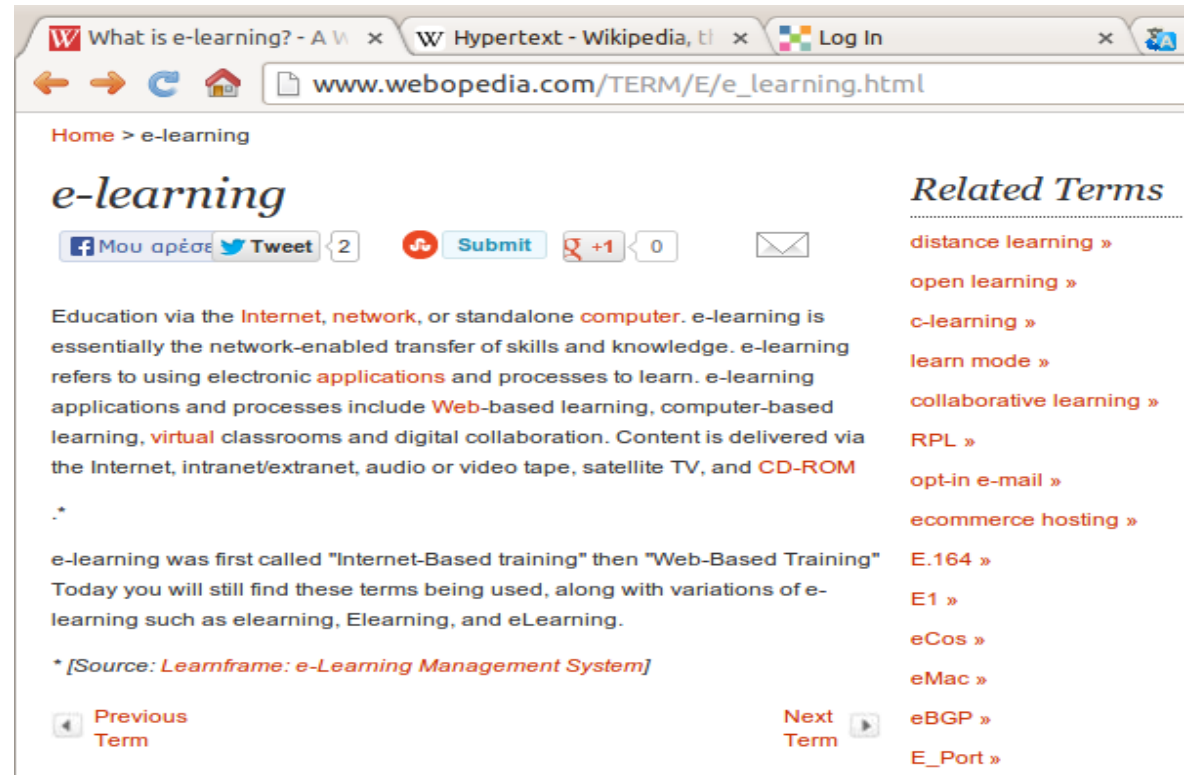

Figure 1 - Exploiting hyperlinks

Online text may also support persons with disabilities or reading difficulties. Readers can easily increase font size; it is also possible to have the text pronounced by the computer automatically using various "text to speech" standalone applications or online readers (e.g., http://media.readspeaker.com).

Another great advantage of hypertext is the possibility of automatic translation of hypertext, which allows readers to study text written in various languages. Moreover, online educational material may become immediately available to any student in the World at no cost.

Other common features offered by online text are:

- Easy navigation within the document. In a digital document (such as pdf, odt, doc etc.) the Table of Contents itself provides hyperlinks to all of its entries; thus the reader can easily and immediately navigate to the expected results, activities, self-assessement questions, answers, suggested further reading sources, bibliography, or any other chapter.

- Easy search for specific terms or keywords.

- Easy incorporation of Pretext, Post-text, Context, Overtext, Paratext, Retrotext, Multitexts and multimedia (Lionarakis, 2001; Andreatos and Katsoulis, 2011). In traditional printed textbooks it is impossible to embed videos, animations, simulations etc; therefore, many official textbooks have companion websites. Also, most (if not all) courses of the HOU use supporting websites, where they post supplementary educational material for further study (readings, past tests, assignment solutions etc.)

- Easy and immediate publishing, update, correction of errors, typos, etc.

- Support for disabled readers, persons with disabilities or reading difficulties. Readers of digital documents can easily increase font size; it is also possible to print digital documents in Braille printers, or even, have text pronounced by the computer automatically.

Information and Communication Technology (ICT) greatly facilitates ODL towards eliminating the teachers' physical distance, by offering flexible, polymorphic and user-friendly multimedia educational materials (Lionarakis, Panagiotakopoulos \& Xenos, 2005). Especially New Media (such as videos) bring the ODL learner closer to 
the face to face model (e.g., by watching the instructor speaking). Furthermore, ICT offers platforms and tools for communicating and collaborating from distance (Andreatos, 2007; Lionarakis, Panagiotakopoulos \& Xenos, 2005). ICT bridges to a large extend the distance between learner and teacher, but also among the students themselves. Commonly available ICT technologies (such as social networking platforms) and tools (such as Skype or various "messengers") cultivate the classmate community feeling in virtual communication (Andreatos, 2007).

ICT minimises not only the cost of the educational portfolio but also the cost of access to new information (Lionarakis, Panagiotakopoulos \& Xenos, 2005). For instance, instructors can post the material in specific sites or even send it by email; moreover, they can easily and instantly modify, update or complete the materials, things very difficult to achieve in print.

In summary, the Web and hypertext can facilitate study, support distant communication and collaboration, save time, incorporate multitexts and multimedia and support disabled readers.

\section{Supporting Learning styles}

\subsection{Common definitions of learning styles}

The learning styles refer to the way we acquire information. Most people have a learning style, a way by which they learn more easily. We can learn by watching, hearing or even touching. We also learn by doing. People also have different types of memory. Some of us remember things more easily than others; some of us remember details while others want to look at the whole picture.

Learning styles were firstly developed by Peter Honey and Alan Mumford (Honey \& Mumford, 1982), based upon the work of David Kolb (Kolb, 1976; 1981; 1984) and they identified four distinct learning styles or preferences: Activist, Theorist, Pragmatist and Reflector (U. Leicester, 2013). Another popular taxonomy is that of James \& Gardner (1995). James and Gardner (1995) define learning style as the complex manner in which learners most efficiently and most effectively perceive, process, store and recall, in their effort to learn. Another useful method is to categorise various learning style models according to social interaction. Others categorise learning style by physical and sensory preferences, e.g., visual, auditory, tactile and kinesthetic (Brown, 1998).

According to the senses used in the learning process, the most common learning styles are: visual, auditory, tactile and kinesthetic. Another taxonomy based on human interaction is the interpersonal vs. the intrapersonal style (Brown, 1998).

Having briefly presented a taxonomy of learning styles, let us now examine how the ODL educational material could support them.

\subsection{Suppporting Honey and Mumford's learning styles}

A printed book is usually written according to the author's preferable teaching style hence favours specific learning styles more than others. There is no possibility to rewrite the book in such a way to support equally well the rest learning styles due to various reasons, cost included. However, the flexibility of electronic text can reverse this situation. Proper web-based educational platforms can present the electronic ODL material in various ways to support the corresponding learning styles.

Web-based Adaptive Learning Environments (ALE) get advantage of technology in order to enrich and maximise the learning experience (Gregoriadou, 2006). ALE's take into account specific characteristics of the learners such as learning style, prior knowledge, user needs and preferences, in order to personalise characteristics such as 
order of presentation of learning objects, feedback, suggestions for navigation through the educational resources and user support.

For instance, to support theorists, an ALE would present theory first, whereas to support pragmatists it could start with videos or simulations demonstrating experiments and present the theory afterwards. To implement this feature, the ALE would retrieve the ODL material structured in a modular fashion such as the WestLionarakis model from a Database (e.g. a "LAMP stack") and would present it to the reader according to his/her learning style, independently of the ODL author's style.

ALEs may also support inquiry learning, collaborative learning (Andreatos, 2007) and the development of meta-cognitive skills.

\subsection{Suppporting other learning styles}

Web technologies can support most the human senses using New Media. New Media is digital media that arose with Web 2.0, the evolution of the Web, in contradistinction to old, traditional media such as press, radio and TV. Videos, podcasts, webcasts and wikis constitute common New Media examples.

Table 1 explains how New Media and the Web can support some representative, common learning styles.

Table 1 - Support to common learning styles by New Media and the Web

\begin{tabular}{|l|l|l|}
\hline Learning style & \multicolumn{1}{|c|}{ Supporting new media } & \multicolumn{1}{c|}{ Supporting technology } \\
\hline Visual & $\begin{array}{l}\text { Pictures, images, charts, videos } \\
\text { (Multi-objects) }\end{array}$ & CMS, LMS, Course Builder \\
\hline Auditory & Soundtracks, podcasts, webcasts & $\begin{array}{l}\text { Text to speech applications, } \\
\text { online readers }\end{array}$ \\
\hline $\begin{array}{l}\text { Tactile and } \\
\text { kinesthetic }\end{array}$ & $\begin{array}{l}\text { Videos, simulations, DIY } \\
\text { assignments and activities }\end{array}$ & $\begin{array}{l}\text { Online video technologies, } \\
\text { flash, Kinect applications }\end{array}$ \\
\hline Interpersonal & $\begin{array}{l}\text { Videoconferencing, chat, wikis, } \\
\text { Computer-Supported Collaborative } \\
\text { Learning applications }\end{array}$ & $\begin{array}{l}\text { Synergo, VoIP, LAMP stack, } \\
\text { MOOCs (e.g. Coursera, edX) }\end{array}$ \\
\hline
\end{tabular}

Massive open online courses (MOOCs) are open online courses aimed at free, open and unlimited participation via the Web. In addition to traditional course materials, MOOCs provide interactive user forums that help build a community for the students and instructors. We must also note that many CMS's and LMS's are available as free and open-source software, fact which promotes and spreads their use.

\subsection{Course Builder}

Andreatos and Katsoulis (2011) have presented the "Course Builder", a web-based tool and environment presenting the ODL educational portfolio after the WestLionarakis model.

Course Builder supports ODL authors in:

- adapting normal digital educational materials for distance education;

- building new ODL courses;

- enriching their courses using Open Educational Resources (OER) in 
multimedia formats;

- adapting available learning materials to various needs, programmes and learning styles (undergraduate programmes, postgraduate programmes, continuing education programmes, etc.).

Course Builder offers the following advantages to ODL learners:

- Course Builder provides a user-friendly interface and presents learners a variety of multimedia OER supporting most learning styles.

- Multimedia learning objects (LO) have various durations and formats; this makes possible their transfer in portable devices such as smart phones, facilitating adult learners to study on the go.

- The tool is web-based, thus providing interoperability and ubiquitous operation.

Course Builder may be used in conjunction with an official e-book used by the ODL institution or even independently. In this latter case, it could be used in combination with OER, open university courses, open web 2.0 educational platforms (such as Wikiversity and WikiEducator) or online encyclopaedias and dictionaries.

Last, the Web technology allows educational researchers to measure the effectiveness of the various tools and suggest the most appropriate to each learner (Gregoriadou, 2006; Karvounidis, 2013). This research will enable the design and implementation of new tools to facilitate study and further enhance the learning experience.

In summary, web-based platforms (LMS's CMS's, ALE's and research tools like Course Builder) can support the various learning styles to enrich and maximise the learning experience. Special ALE's can also detect learners' learning style in order to suggest the proper environment. Web technology can help transforming the educational processs from teacher-oriended to student-oriended (Lionarakis, Panagiotakopoulos \& Xenos, 2005).

\section{Discussion and conclusion}

About a decade ago, technological companies launched ambitious, complicated, concentrated and expensive "all-in-one" LMS's, often underestimating learners' personal needs. Meanwhile, Web technology evolved and today a large number of free technologies, platforms, applications, new media and OER is widespread and available for use in ODL and can cover specific and individualised needs.

- Today's students widely use ICT and social networking in many activities including learning.

- A huge amount of OER and online courses is available online.

- ICT infrastructure enables access to MOOCs and educational resources worldwide.

- Free LMS's facilitate and expedite the publication of learning material.

- Portable devices enable m-Learning and support mobile learners.

- ICT can support the special characterics of ODL educational material.

- ICT can implement the structured delivery of ODL courses exploiting OER.

- ICT can support learning styles, user needs and personalised learning to promote Open and Distance Education.

Table 2 presents some ways in which Web \& New Media technologies may support the special functions needed by the ODL educational material. 
Table 2 -- Web and New Media technologies supporting ODL educational material features

ODL material task

Proper presentation of the educational portfolio
Web \& New Media technologies possibilities

Special web-based platforms (e.g. Course Builder) facilitate the presentation of the educational portfolio and help authors to build an ODL course according to a specific format (such as the West-Lionarakis model)

Additional bibliography and Links to online courses, videos, simulations, etc. sources for parallel or further study

\begin{tabular}{|l|l|}
\hline $\begin{array}{l}\text { Explanation of terms, } \\
\text { keywords }\end{array}$ & $\begin{array}{l}\text { Links to definitions in other chapters or online } \\
\text { encyclopaedias \& dictionaries }\end{array}$ \\
\hline Feedback & Playback recorded messages in educator's voice \\
\hline Facilitate study, review & Change level of view (zoom-in, zoom-out) \\
\hline Exam preparation & Links to online courses, OER, problem sets, exercises \\
\hline
\end{tabular}

In conclusion, ODL educational material for the web should follow specific guidelines, discussed in detail throughout the paper, in order to:

- comply with the principles of ODL educational material;

- present the ODL porftolio in a usable, straightforward and ergonomic manner;

- take into account online reader's behaviour and web usability rules; and

- support learning styles.

To recap the main points, ODL educational material for the web should be written in small chunks using an unofficial, user-friendly style, adopting a hierachical and modular structure, facilitating study and navigation, taking advantage of hyperlinks, incorporating readings, multimedia and reusable educational learning objects (such as OER) tagged with metadata, bearing in mind the learners' needs from the very beginning.

On the other hand, LMS technologists should invest in the development of systems supporting personalised learning, bearing in mind the pedagogical science findings, as well as, the learners' needs.

The Web and New Media offer new, unique possibilities to ODL learners and teachers as well. However, things are still evolving, so, maturity is expected in the future. Therefore, the author believes that the future of ODL lies on the Web.

\section{References}

Andreatos, A. and Katsoulis, S. (2011). An automatic, web-based tool and environment supporting ODL with OER. In A. Lionarakis (Ed.), Proceedings of the 6th International Conference on Open and Distance Learning, 4-6 November, 2011. Available on line from: http://icodl.openet.gr/index.php/icodl/2011/paper/view/54/51.

Andreatos, A. and Katsoulis, S. (2012). Using Open Educational Resources in Course Syllabi. The American Journal of Distance Education, Vol 26, No 2, pp. 126-139. DOI: 10.1080/ 08923647.2012.663307

Andreatos, A. (2007). Collaborative learning in an ODL framework. In A. Lionarakis (Ed.), Proceedings of the 4th International Conference on Open and Distance Learning, 27-29 November, 2009 (Vol. B, pp. 704-712). Athens, Greece: Propombos.

Brown, B. L. (1998). Learning styles and vocational education practice. Practice Application Briefs, Center on education and training for employment, College of Education, The Ohio State University, pp. 1-2.

Gregoriadou, M. (2006). Adaptive Learning Environments. Proceedings of the 5th Pan-Hellenic 
conference of "ETPE", 5-8 October 2006 (pp. 57-66). Thessalonica, Greece.

Honey, P. and Mumford, A. (1982). The manual of Learning Styles. Maidenhead, Peter Honey.

James, W. B. and Gardner D. L. (1995). Learning styles: Implications for distance learning. New Directions for Adult and Continuing Education, Vol 1995, No 67, Autumn, pp. 19-31 http://onlinelibrary.wiley.com/doi/10.1002/ace.36719956705/abstract

Karvounidis, T. (2013).Methodological Framework and Evaluation of Social Networking Technologies in the Educational Design (unpublished PhD thesis). Univ. of Piraeus, Piraeus.

Kolb, D. A. (1976). The Learning Style Inventory: Technical Manual. Boston, MA: McBer.

Kolb, D. A. (1981). Learning styles and disciplinary differences. In A. W. Chickering (Ed.), The Modern American College. San Francisco: Jossey-Bass.

Kolb D. A. (1984). Experiential Learning experience as a source of learning and development. New Jersey: Prentice Hall.

Lionarakis, A. (2001). Open and Distance polymorphic education; issues of a qualitative approach for the design of educational materials. In A. Lionarakis (Ed.), Perspectives and questions about Open and Distance Learning. Athens: Propombos.

Lionarakis, A., Panagiotakopoulos, C. and Xenos, M. (2005). Open and Distance Learning: tools of information and communication technologies for effective learning. In A. Lionarakis (Ed.), Open and Distance Learning, vol D, Pedagogical and Technological applications. Patras: Hellenic Open University.

Nielsen, J. (2000). Designing web usability. Indianapolis: New Riders.

Race, Ph. (1989). The Open Learning Handbook - Selecting, designing and supporting Open Learning materials. London: Kogan Page.

University of Leicester (2013). Honey and Mumford. Accessed June 22, 2013. http://www2.le.ac.uk/departments/gradschool/training/resources/teaching/theories/honeymumford 